\title{
Development of Executive Functions and Support Systems for Student Teachers in Thailand
}

\author{
Nongluck Manowaluilou ${ }^{1}$ \\ ${ }^{1}$ Faculty of Education, Kasetsart University, Bangkok Thailand \\ Correspondence: Nongluck Manowaluilou, Department of Vocational Education, Kasetsart University, Bangkok \\ Thailand. Tel: 66-093-5410-5642. E-mail: fedunlm@ku.ac.th
}

Received: October 4, 2021

Accepted: November 12, 2021

Online Published: November 18, 2021

doi:10.5539/hes.v11n4p116

URL: https://doi.org/10.5539/hes.v11n4p116

\begin{abstract}
This study aims to investigate the development of executive functions (EFs) for pre-service teachers, their issues during teaching practice, and their motivations for entering the teaching profession. EF self-assessment questionnaires, logbooks, structured in-depth interviews, and support system evaluation forms were used to collect the data. The theory has suggested that school field experiences are particularly effective in student teacher development at the grade level. This study demonstrated a positive association between student teachers' EFs using four years of data from 45 pre-service teachers participating in teacher preparation programs. Fifteen pre-service teachers attending the fifth year of their teacher education program at a university in Thailand. This longitudinal study used four years (during 2017-2020) of data.
\end{abstract}

Keywords: executive functions, pre-service teachers, teacher education

\section{Introduction}

\subsection{Introduce the Problem}

Teacher preparation is a years-long process of developing new teachers. When training these students in pedagogy, teaching application skills is a systematic procedure because it requires them to develop basic teaching skills and learn classroom-related skills, idea-generating skills, classroom management skills, and solution-seeking skills.

The teacher education program's typical duration in Thailand has been five years, but some programs have recently shortened the time to four years. This change concerns many professional teacher development professors because they posit that the students' teaching practicum's reduced duration could negatively affect new teachers' quality (Calderhead \& Sherrock, 1997; Jones, 2005). Notably, most pre-service teachers would prefer to shorten the program and begin working after 4-rather than 5-years. However, teacher educators have a firm belief in Senge's 11 Laws of the Fifth Discipline, whose philosophy is "faster is slower," that is, unqualified teachers in the system would slow professional development in the long term. The mastery of teacher education skills, such as those related to professionalism and work ethics, is highly desired in the professional teaching arena.

Reducing the amount of time would cause a major change in teacher education programs. However, this was a government policy that teacher education programs must abide. Therefore, we only scope our study only at five years program and report the result to support the idea that the duration was matter in producing qualified teachers.

Executive functions (EFs) is a theory to explain as a diverse group of specific cognitive processes collected together to direct cognition, emotion, and motor activity, including mental functions associated with the ability to engage in purposeful, organized, self regulated, goal directed behavior (Banich, 2009). Few researchers have focused on executive functions and teacher development, especially in Thailand's teacher development program. The hypotheses of this study focused on EF development, teaching performance, impact on personal growth, and selection of teaching materials and activities. Pre-service teachers should receive proper consultations and suggestions during practicum to prevent any discouragements or abandon the decisions to become a teaching. Insufficient amount of teacher preparation time could result in the decision to turn away from the teaching careers and resulted in teachers' shortages in the future. Therefore, the Pre-Service Teachers' Support System 
(PSTSS) was initiated to develop EFs in pre-service teachers and assist pre-service teachers from any despair or discouragement that might occur.

Pre-service teachers attending the teacher development process should learn to demonstrate systematic, higher-order thinking (Sulpeter, 2003). Starting with personal mastery, they should create mental models that lead to creating shared visions and expressing these shared ideas and visions could lead to team learning. Accepting ideas and self-improvement could occur and subsequently develop a systemetic thinking. Pre-service teachers review the multiple case studies in their classes to prevent any malpractice that could occur from unknown "solutions." These students advance through multiple stages of preparation, in which their knowledge, endurance, readiness, and professionalism are developed (Dawson, 2010).

The objectives of this study are: 1) to examine EFs of pre-service teachers enrolled in teacher education program, and 2) to study the pre-service teachers' support system (PSTSS) that could enhance student teacher's decisions to pursue career in teaching.

By applying the EFs as practical tools to teach EF strategies, also called EF skills, for organization, time management, planning, prioritizing, flexible thinking, self-monitoring and checking, and memory, student teachers develop the self-understanding to know which strategies are successful for them. We study the EFs' levels of student teachers, and how the PSTSS could help student teachers in coping with any mental and emotional stress and episodes of burnout. The counseling sessions are initiated accordingly for the student teachers at least four to five times during a teaching practicum to ensure that they have the support they need. Other support system tools are arranged, for example, classroom action research suggestions, guidelines, and teaching experiences.

\section{Literature Review}

\subsection{Teacher Preparation Goals}

Teacher education programs aim to educate undergraduate students by applying pedagogical and content knowledge. These teachers must be ready to teach in schools after four years of content knowledge learning and two teaching practicum semesters. The preparation provided to students by teacher education programs, including education on various necessary skills, for example, classroom management, self-control, and ethics, attempts to ensure their smooth transition from academics to their new career as teachers in school settings. The teacher development process is complicated and thus produces only 20 to 30 trained teachers per year. After completing the general and teaching profession courses, students must enroll in a student teaching practicum course.

The teacher education practicum course aims to personalize the learning activities to prepare and develop teachers' pathways. Most students find that changing their role from student to pre-service teacher is challenging; therefore, the education practicum course is offered to promote professional growth, such as their potential, path, and pace and balance goals (Jones, 2016). The literature has described a new approach called the PSTSS, which provides pre-service teachers with personalized, high-quality teacher preparation and opportunities for EF development, and ongoing professional learning development.

\subsection{Student Teaching Programs}

In school settings, pre-service teachers must present satisfactory teaching skills, prepare instructional tools or media, manage classrooms, and work with experienced teachers. Teaching skills can be accumulated through years of learning, observing, and practicing. Unexperienced pre-service teachers find this challenging; therefore, a practicum of two semesters is required. These pre-service teachers become familiar with students, content, learning styles, lesson planning, the curriculum, and their school's culture and environment. EFs have been proved essential in assisting pre-service teachers with acceptable responses (Dawson, 2010).

The recent criticisms from veteran educators highlight a concern: shortening the teacher development program/course from two semesters to one semester results in negative consequences. Because the teaching profession is considered a teaching career pathway and that pre-service teachers acquire teaching skills before graduation, novice teachers must first spend time as pre-service teachers. They are professionally trained and closely supervised by cooperating teachers, university supervisor and other professionals.

In the twenty-first century classroom, teachers must transform into coaches who inspire and motivate students to learn. This transformation requires changing the teacher development process by educating pre-service teachers in advanced lesson planning, facilitating activities, and technological involvement. The changing role of pre-service teachers is presenting new challenges for teacher education programs across Thailand. The "teaching and coaching" model, a collaborative effort between university education programs and schools, has been 
implemented to assist pre-service teachers overcome these challenges (Kelley, 2004). This model encourages pre-service teachers in many aspects that aim to provide a good teaching impression, hopefully leading to improved teaching and learning outcomes (Loughran, 2014).

The structure of teacher education programs in Thailand is similar to that used in the United States: 3 years of pedagogical and content knowledge, one year (two semesters) of micro-teaching experience, and one year (the fifth year) of teaching practicum. The first semester's purpose is to provide time for pre-service teachers to adjust to their new environments, students, administrators, cooperating teachers, and school boards.

The teaching content must be prepared and align with the Teacher Council of Thailand's core curriculum standards on Professional Standards and Ethics BE 2548 (2005) (Gazette, 2005). Therefore, to avoid unexpected or inappropriate content, the content must be cross-checked by cooperating teachers before being taught in the classroom. Teaching skills must be highly organized in a systematically presentable manner. The objective is to assist pupils of the pre-service teachers with learning or improving specific computer skills, in-class activities, instructional games and uphold the applicable laws and ethics. In the second semester of the fifth year, the pre-service teachers conduct classroom action research for one semester. Through this process, the pre-service teachers gain research experiences and develop a systematic approach to correcting classroom problems.

\subsection{EF in Pre-service Teacher Preparation}

EFs, self-efficacy and self-regulation skills are the mental processes that enable humans to plan, prepare, reason, make decisions, initiate tasks, focus their attention, remember instructions, and execute multiple tasks successfully (Densen et al., 2011; O'Brien \& O'Hare, 2007; Bandura, 1997; Lunenberg). Teachers are normally busy managing their students, and their brain needs to multitask, including managing distractions, prioritizing tasks, setting and achieving goals, and controlling impulses. Because pre-service teachers are new to teaching and other classroom obligations, these require them to exhibit a significant amount of EFs. Poorly executed EFs can lead pre-service teachers to have poor judgment, low productivity, and an inability to retain their jobs (Bailey, 2007).

EFs are also important to harmony because pre-service teachers with poor EFs have more difficulty getting along with pupils and are less dependable and more likely to act impulsively than pre-service teachers with high-quality EFs (Eakin et al., 2004). The dissemination of EFs through pre-service teachers as role models are essential in lessening the severity of social problems, such as when pre-service teachers demonstrate their ability (or inability) to control learners' aggression (Broidy et al., 2003; Densen et al., 2011; Moffitt et al., 2011), and improving pupil's readiness to learn. There are various problems in schools, for example, illiterate learners; thus, to prepare for class, most of the time is spent developing course content, and several hours are spent practicing teaching. In general, these assertions are particularly true for the inhibitory control components of EF. Notably, EF also helps improve pre-service teachers' academic performance. Also, successful performance in complex dynamic environments depends on a situational awareness (O'Brien \& O'Hare, 2007).

Meltzer (2010) found that EFs regulate an individual's goal-directed behavior and contextualize intended actions based on knowledge and experience, current situational cues, expectations of the future, and personally relevant values and purposes. EFs provide a sense of readiness, agency, flexibility, and coherence; are related to multiple intelligence theory; emerge from intrapersonal intelligence; provide the computational capacity to discern and use information about oneself; and regulate an individual's behavior by orchestrating the other intelligence toward self-relevant purposes within and across temporal, social, and psychological contexts.

Table 1. Synthesizing the development of executive functions

\begin{tabular}{lcccccc}
\hline Elements of EF & $\begin{array}{c}\text { Bailey } \\
(2007)\end{array}$ & $\begin{array}{c}\text { Eakin } \\
(2004)\end{array}$ & $\begin{array}{l}\text { Broidy } \\
(2003)\end{array}$ & $\begin{array}{l}\text { Densen } \\
(2011)\end{array}$ & $\begin{array}{l}\text { Meltzer } \\
(2010)\end{array}$ & $\begin{array}{l}\text { Preston } \\
(2017)\end{array}$ \\
\hline 1) Personalized learning environment & $\bullet$ & $\bullet$ & & & & \\
2) Executive functions help with social issues & & & $\bullet$ & $\bullet$ & & \\
3) Goal-directed individuals & & & & & & \\
\hline
\end{tabular}

Note: presents evident as an essential element

Metacognition, inhibiting habitual responses, delaying gratification, adjusting to changing rules, and making decisions under uncertain circumstances can be implemented to balance schoolwork and a student's behavior (Zelazo et al., 1997). Undergraduate students with poor EFs may have weak inhibitory control (i.e., less persistent, more impulsive, and lower selective attention). Poor EFs cause instability in future teachers' careers. EFs can assist pre-service teachers with emotional control, for example, by behaving nicely and thus being a 
satisfactory role model for students.

\subsection{Classroom Action Research}

One of the many requirements of students endeavoring to graduate from teacher education programs that they are having difficulty with is completing classroom action research. They are expected to generate problem statements, research methods, and findings for their classroom research projects. They must conduct this classroom action research in the second semester to correct pre-service teachers' problems with their teaching skills before completing the overall teacher education program. Before embarking on this project, the pre-service teachers have little to no experience conducting classroom action research. Generating research questions and problem statements are challenging even for veteran researchers. Notably, a close relationship between the pre-service teachers, the supervising teachers, and cooperating teachers can help the former overcome this challenge (Cole, 1991).

Classroom action research requires adequate time for pre-service teachers to prepare materials, content knowledge, and research instruments and collect data. An inadequate amount of teaching time results in many problems in this type of research. For example, sports activities, new year's events, and some private schools' long Christmas holidays result in canceled classes, limiting the time spent with students to collect data for classroom action research. Thus, careful lesson planning is recommended to all pre-service teachers during their small group discussions and one-on-one consultations. To solve the problem of inadequate teaching time, pre-service teachers use web-based learning and plans to collect data online. For example, they post the materials, class notes, assignments, and homework online and use school educational websites (i.e., edmodo.com) for evaluations and as a scoreboard.

\subsection{Student Teachers' Progression}

The first semester of the fifth year is the transitional period during which a student teacher becomes a professional teacher. Pre-service teachers learn to understand new roles, schools' regulations, and how to adapt to new environments and increase their self-confidence in the classroom. Weighing the pros and cons of the first few months can help pre-service teachers understand their ambitions and whether a teaching career fulfills their expectations. The need for early intervention during teaching is critical because novice teachers can have difficulty with disadvantaged students (Evans \& Rosenbaum, 2008; Evans \& Schamberg, 2009; Hackman \& Farah, 2009; Lengua, et al., 2007: Noble, McCandliss, \& Farah, 2007; Noble et al., 2005: Raizada \& Kishiyama, 2010; Sektnan, et al., 2010). During this first semester, a support system is important and relevant to a student teacher's determination to become a teacher (Darling-Hammond, 1998).

A support system comprises of the cooperating teachers, administrators, supervising teachers and pre-service teachers' peers who work closely together (Bowman, 1979; Burstein, 1999) to support an eco-learning system. Performing well in the classroom does not guarantee success in schools because other factors, such as relationships with cooperating teachers, work, and lesson planning, require extra time and extensive effort. Some pre-service teachers can job-shadow cooperating teachers, which is an effective means to learn duties other than teaching. The support system is related to pre-service teachers' progression and could develop into a collaborative skill.

\section{Method}

This study conducted a mixed method approach based on an interpretive paradigm to shape pre-service teachers within the context of teaching practice as experienced by 15 pre-service teachers during their teacher education program.

To examine the EFs of pre-service teachers enrolled in teacher education program. This was based on data analysis and expert reviews on content analysis from document and research articles from EFs, support system, student teachers' roles, and student teachers' performances. This study used the following instruments: an EF self-assessment questionnaire, pre-service teachers' logbooks, conference documents, successful case study, classroom participatory action research, pre-service teachers' reflections. The data was analyzed based on teaching performances, EFs, classroom management, and the PSTSS evaluation form of pre-service teacher's content analysis, which enable the author to make sense of how teacher preparation program EF levels, and consulting activities influence a decision to pursue a teaching career in the future.

To examine the development of the student teachers' support system (PSTSS) that could enhance student teacher's decisions to pursue career in teaching, the interviews, self-reflection essays and observations were used. Structured in-depth interviews were used for collecting data from pre-service teachers in teacher education preparation programs. To develop an in-depth understanding of the essence of Thai pre-service teachers' 
experiences of teaching, we used a PSTSS conceptual framework that study per-service teachers' feedback towards the teacher preparation program, EFs levels (Activation, focus, effort, emotion, memory and action), and consulting activities of PSTSS to understand whether they would affect the decision to become teachers in the future.

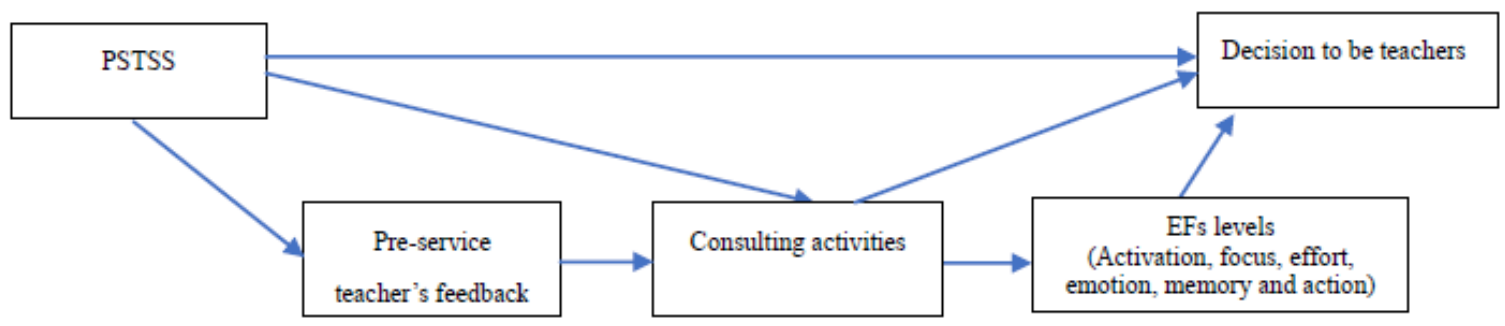

Figure 1. Conceptual framework

To understand pre-service teachers' EFs, multi-method evaluations were used throughout the research method. The methods included reviewing of self-reflections in logbooks, in-class observation, teaching logs, group discussions. Teaching logs, self-reflections, and group discussions were the main sources of data. It was designed to encourage pre-service teachers to reflect on their knowledge, EFs' levels and teaching performances gained from PSTSS.

\subsection{Participants}

This study sample comprised 15 pre-service teachers attending the fifth year of their teacher education program at a leading university in Thailand. This longitudinal study used four years (during 2017-2020) of data from 45 elementary to high school teacher preparation programs and assessed pre-service teachers' feedback. The data were from various sources: in-depth interviews performed after in-class visits, participatory observations, logbooks, and student-teacher conferences. The researcher used an EF assessment to assess pre-service teacher's: attention, inhibitory control, working memory, organization and planning, concept formation, set shifting, and word and idea generation while practicum training. Each student teacher was assigned a pseudonym to ensure anonymity. This study assessed the pre-service teachers' performances and their students' achievement gains in computer and technology courses by interviewing six pre-service teachers. Pepper, Jane, Dianna, Cheryl, Will, and Keane were selected among the 15 pre-service teachers for further investigation because they exhibited good and moderate EFs relating to pedagogical content knowledge, dissemination, and overall performances.

\subsection{Research Design}

Objective 1 aimed to study EFs of pre-service teachers enrolled in teacher education program. This was based on data analysis and expert reviews on content analysis from document and research articles from EFs, support system, student teachers' roles, and student teachers' performances. The EFs of pre-service teachers were measured on a 5-point scale, ranging from very low (1) to very high (5). This is the 26-item version of the original questionnaire and measures subjective EFs in five dimensions; activation, focus, effort, emotion, memory, action; and decisions to become teachers.

Objective 2 aimed to examine the development of the student teachers' support system (PSTSS) that could enhance student teacher's decisions to pursue career in teaching. The PSTSS was developed based on key consideration and a conceptual framework (shown in Fig.1) of student teachers' experience with tasks and teaching activities that could lead to greater task performance (Schukajlow and Krug, 2014). Three experts reviewed the content validity and congruency of the PSTSS session and provided feedback; some content was adjusted accordingly. The ratings of PSTSS were measured on a 5-point scale, ranging from very low (1) to very high (5).

\subsection{Data Analysis}

The PSTSS impacts on pre-service teachers were analyzed using research and development based on quantitative techniques from the same instructors, and same groups of pre-service teachers. The survey included items pertaining to demographic characteristics of pre-service teachers, EFs (organization, time management, planning, prioritizing, flexible thinking, self-monitoring and checking, and memory), and evaluation of PSTSS. The data were analyzed using a descriptive data analysis. Reliability was calculated by measuring internal consistency in term of Cronbach's alpha method. The instruments were statistically correlated in the same direction with the 
correlation coefficients between 0.27-0.49. The Cronbach's alpha of the instruments (Thai version) was 0.77 .

Results of interview were analyzed using a content analysis. Using a thematic analysis allowed researcher to highlight key findings of PSTSS practices that enhance pre-service teacher's experiences, teachers' perceptions, cognitive skills, task management skills, stress management, students' achievement gains during their internship, and aspects of pre-service teachers' stories.

To analyze data from teaching logs, self-reflections, group discussions and student-teacher conferences; field notes and transcripts were combined to enhance validity. By transcripting the self-reflections and teaching logs, we identified EFs' key indicators as categories of "organization" and "planning" and coded them on documents. Sub-categories such as teaching strategies, prioritizing, flexible thinking, self-monitoring, and memory were identified and coded afterwards. The codes were compared among their consistencies and differences. The categories were later reduced, refined, and finally formulate themes to explain the meaning of data.

\section{Results}

In this experiment on mental support, the case studies' findings have demonstrated which EFs improve teaching performances, classroom management, and the PSTSS. According to Kenney (2017), self-control is an EF and attention of the brain, "sustaining attention is ignoring the distractions and dialing in on what matters." EF development is critical for all pre-service teachers to support as many aspects as possible of issues they may have. Data were collected from various sources, with double-blind annotation of interview transcriptions being used to identify prominent themes as well as from the thematic analysis of the transcriptions of participatory observations, interviews performed after in-class visits, logbooks, and student-teacher conferences. The constant comparative method of data analysis was used to analyze and interpret the data. The method of data analysis allowed for continuous comparisons and the construction of categories for the data. Tentative themes that emerged from the data were noted. This study assessed the pre-service teachers' perceptions, cognitive skills, task management skills, stress management, and their students' achievement gains during their internship. Many cases of pre-service teachers have demonstrated various issues related to, for example, teaching techniques, problems, and adaptations. The PSTSS was developed as a result of the PSTSS' needs assessments. It is a source for pre-service teachers to share their insights, opinions, experiences, teaching methods, questions, and other issues. It is also a support system through which cooperating teachers provide case-by-case directions, explanations, friendly consultations, and suggestions to pre-service teachers, encouraging pre-service teachers to enter the teaching profession (Kelly, 2004).

\subsection{EFs}

The pre-service teachers' self-assessment of EFs was administered before and after their teaching practicum. Table 2 presents the results, and there are six EFs aspects: activation, focus, effort, emotion, memory, and action. The rating scale is as follows: 0 (never), 1 (rarely) 2 (occasionally), 3 (often), and 4 (usually).

Table 2. Aspects of executive function $(n=15)$

\begin{tabular}{lllll}
\hline Executive Function & \multicolumn{3}{l}{ Before } & \multicolumn{2}{l}{ After } \\
\cline { 2 - 5 } & $M$ & $S D$ & $M$ & $S D$ \\
\hline Activation & 3.71 & 0.94 & 3.78 & 0.67 \\
Focus & 3.27 & 0.78 & 3.34 & 0.68 \\
Effort & 3.66 & 0.91 & 3.71 & 0.79 \\
Emotion & 3.44 & 0.74 & 3.46 & 0.91 \\
Memory & 3.46 & 0.76 & 3.72 & 0.77 \\
Action & 3.24 & 0.81 & 3.33 & 0.97 \\
Overall ratings & 3.46 & 0.82 & 3.56 & 0.80 \\
\hline
\end{tabular}

The highest $\mathrm{EF}$ before entering teaching is activation, for which pre-service teachers rate themselves the highest among the six aspects. The overall EFs' aspects are rated higher than the baseline after one year of self-development and teaching preparation in the teaching practicum (Table 2).

The pre-service teachers were interviewed, and six cases were reported as critical because they affected the trajectory (the negative or positive feedback loop). The three cases of moderate to good EFs and the three cases of poor to moderate EFs are as follows. The first case was "Pepper;" he taught a computer course to 11-year-old students. He demonstrated poor EF and an inability to control his classroom and was easily distracted. His cooperating teachers were worried about "his irresponsibility and inadequate judgment." While teaching, Pepper often had insufficient motivation and did not encourage his students' involvement in activities; however, he 
demonstrated satisfactory teaching performances. Because Pepper was a role model for some of his students, he had an opportunity to develop his students' EFs and self-regulation skills, resulting in lifelong benefits.

The case of "Jane," who taught a business course to 12-year-old students in a well-known public school in Bangkok. Jane had good EFs and a great intention to teach. Thus, she could encourage her students' positive behaviors and allow them to make healthy choices for themselves. She also used various types of teaching tools, games, and card and board games that allowed her students to exercise their working memory and promoted mental flexibility in teaching, planning and classroom strategy. Jane used a board game that allowed students to have fast responses, challenged their ability to pay attention, and developed business decision-making skills. Also, she believed in students' brain development; thus, she used a brain-based technique to involve students in her teaching.

Therefore, Jane used many fancy games requiring her students to hold in their working memory the complicated information, rules, characters, strategies, and materials necessary to develop business planning and attain self-determined goals that continued to test cognitive flexibility. Instead of the normal summarization frequently used in other classes, Jane proposed the "flip-through" techniques. While flipping through a deck of name flashcards, whoever could guess the name of the card that would be selected would not be selected for discussion. The students eagerly guessed the names and attempted to avoid being picked. Once the names were chosen from the name flashcards, the students were loosened up and made ready to participate in the in-class discussion.

The third case of good EFs was Dianna; she taught a computer course to 8-year-old students at a well-known private school in the center of Bangkok. Her students were eager to learn, participate, and be involved in all types of school activities. She created a board game that contained materials that helped her deliver basic computer components and concepts. Subsequently, she used a computer game (i.e., Kahoot) to test her students' cognition. This challenge developed students' EFs and helped them attain self-determination goals.

During the sixth session (the sixth week of the second semester of fifth year), Will expressed concerns about time management and requested a special one-on-one PSTSS consultation. Will had moderate to high EF's and difficulties denying requests from cooperating teachers, administrators, and other teachers. A downward spiral of self-hesitation and low expectations resulted in him not wanting to teach. Will participated in a session with the PSTSS that cooperated with the EFs by reinstating a goal and requisite abilities and attaining self-reinforcing and positive feedback with better EFs. Will decided to keep on his second attempt until he attained his goal. Notably, Will was on probation for one semester and was suspended from teaching because he posted inappropriate content on social media.

Cheryl taught computer courses at a small public school in Bangkok's outskirts. During the fifth PSTSS session (the fifth week of the second semester), she expressed her concern about leaving the teaching profession. She was unable to manage her students' behaviors and increasing expectations of the content knowledge. Other pre-service teachers (approximately 73\%) reported that they extended activities' hours, causing exhaustion, and decreasing the time available for teaching preparation and other engagements. However, Cheryl was hesitant to leave the teaching profession, and the others were indecisive.

Keane who had moderate to poor EFs, refers to a student teacher concerned with education uncertainty. He is insecure regarding receiving a job placement after graduating from a five-year educational program. Because of the many requirement changes by the OBECs and the Teacher Council of Thailand, the vulnerability to pre-service teachers' uncertainty with poor EFs will probably increase, and they will need additional reassurances (Adler \& Newman, 2002; Gianaros, 2011). Although the solution is at the administrative level, the PSTSS provides pre-service teachers' mental support and encouragement to manage multiple issues (Kagan, 1992).

A small difference between pre-service teachers with poor EFs and those more advantaged in EFs can lead to gaps in performance, achievement, and mental health. Early detection and possible intervention can potentially assist pre-service teachers with teaching and decisions, reduce their burdens, and remain the possibility of pre-service teachers in teaching professions.

\subsection{Adjustment and Adaptation}

Pre-service teachers experienced various obstacles while in the schools they chose for their teaching practicum because they were unfamiliar with the new school surroundings. The new environment created stress for some pre-service teachers; thus, adaptation was necessary. School cultures, new friends, new individuals, and new cooperating teachers can be redundant. Pre-service teachers must have mature conversations with school board members, cooperating teachers, other teachers, and students; thus, they have many new experiences (Conley, 
2005). In the pre-service teachers' second semester, after fulfilling the course requirements and attaining the worthwhile feeling of teaching, they became more comfortable teaching classes and with school administrators, students, classroom management, teaching loads, and their duties (Bellanca \& Brandt, 2011). The incessant tension among pupils, parents, administrators, pre-service teachers, and students decreased. The classroom environment improved, increasing pre-service teachers' confidence in their teaching. During this stage, pre-service teachers enjoyed the teaching profession more than at the beginning of the semester; they were keen on content knowledge, time dividends, morals, and ethics.

\subsection{PSTSS}

PSTSS sessions were introduced to the pre-service teachers at the beginning of the first half of the second semester of 2017 academic year. After the support system needs assessment, the student teacher should have a support system that would provide support while teaching. Therefore, the PSTSS was assimilated based on consultations, pre-service teachers' progression, EF development, and other relevant issues using a social media platform. There were five elements of the PSTSS: materials and classroom activities, consultations, progression, EF development, and other issues (Table 3). Each student teacher could pose inquiries on a "LINE" program, and cooperating teachers and other pre-service teachers would answer.

Table 3. Student teacher's support system assessment $(n=15)$

\begin{tabular}{lll}
\hline Factors & $M$ & $S D$ \\
\hline 1) Materials and activities & 4.01 & 0.87 \\
2) Consultation & 4.23 & 0.61 \\
3) Progression & 4.41 & 0.46 \\
4) EFs' development & 4.33 & 0.39 \\
5) Impact on personal growth & 4.02 & 0.44 \\
Overall ratings & 4.20 & 0.56 \\
\hline
\end{tabular}

PSTSS was presented by using two methods: an online platform and a private consultation. PSTSS provides support for classroom action research, classroom management, and teaching techniques. Because some cooperating teachers had little to no classroom action research experience, they could not provide updated advice. Additionally, new teaching techniques that led to classroom research design were encouraged in the second semester of the fifth year. Therefore, the PSTSS online platform provided information on classroom action research (i.e., basic information), classroom action research procedures, statistical analysis, and classroom action administration.

\subsection{Classroom Action Research Concerns}

Pre-service teachers were worried about collecting data during the second semester of their fifth year because of the many national holidays; therefore, they had to prepare their research designs and methods. Notably, writing and executing lesson plans while conducting classroom research is challenging, especially for pre-service teachers, who are novices in the field. Teaching logs, interviews, group discussions, and self-reflections were analyzed to ensure the research results' integrity and reliability. Pre-service teachers with high EF's successfully managed both their research and teaching by using lesson plans, collaboration, and pedagogical preparation, and finishing their tasks on schedule. Nevertheless, constructing citations and finding references were reported as substantial burdens by Thai students, and they predicted problems when copying and pasting information from research and articles. The first conference and several PSTSS sessions emphasized citing, paraphrasing, avoiding plagiarism, and other research concerns to avoid these issues.

\section{Discussion}

The development of EFs is essential in retaining students in education programs. This study's results have demonstrated that pre-service teachers with good EFs perform well; maintain self-regulation, self-development, and self-adjustment; and appropriately manage challenges. Pre-service teachers with good EFs can perform well with schoolteachers, design lesson plans, manage classrooms, and demonstrate satisfactory progression. However, pre-service teachers with poor EFs are prone to having problems with cooperating teachers and have several school responsibilities issues. Allowing pre-service teachers with poor EF development to start teaching sets them on a negative trajectory that is challenging and expensive to reverse. PSTSS was initiated to assist with such problematic cases and develops EFs and personal growth (mean = 4.41). The consulting times with cooperating teachers and supervising teachers are allocated to pre-service teachers to discuss their research progress, personal growth, EF development, and solutions to reported problems. A support system is important to 
pre-service teachers because it provides them with guidelines, teaching tools, guidance, and assistance.

We argue that although good EFs are not required for pre-service teachers, they are a satisfactory predictor of whether pre-service teachers will perform well in schools and pursue careers in teaching. Although EF development would ideally begin in childhood, development in adulthood is possible. Pre-service teachers who demonstrate poor EF must improve this aspect of themselves before entering school settings because only then can they be viewed as good role models for students. Thus, the argument is whether too much is expected from first-time teachers entering schools (Feiman-Nemser, 2001). The operation of EFs is complex and differs by age and experience. Therefore, the EF parameters for pre-service teachers's second attempt are more complicated and challenging than the first attempt.

\subsection{PSTSS}

The supervising teachers provided the pre-service teachers with suggestions to improve their school performance, feedback and encouragement, and directions to conduct research properly (Flores, 2004). During the PSTSS sessions, pre-service teachers were encouraged to share their experiences and the techniques they had learned in their schools, cooperating teachers, and themselves. The lesson plans and activities were assessed before the planned teaching was executed to realize the learning objectives, teaching methods, and learning outcomes. When pre-service teachers observed concerns that could be investigated, they were encouraged to conduct classroom action research. They would learn from their teaching and by sharing their knowledge with other teachers and being more responsive to the findings of other researchers (Smagorinsky \& Jordahl, 1991).

However, the pre-service teachers reported in their logbooks an inability to motivate their students to participate in classroom activities or discussions, reflecting in their poor self-esteem. Because culture plays a vital role in students' performances, a notable point is that in Thai society, arguing or debating with adults is considered inappropriate. This cultural aspect resulted in the students' reluctance to disagree, argue, or discuss certain topics because they had learned since childhood not to share their opinions.

\subsection{Adaptation and Adjustment}

Teaching can be challenging, especially for new pre-service teachers, because they must adapt and adjust their teaching practices. Managing this environment is difficult for new teachers, and they might become frustrated because of the new environment, seemingly unmanageable school systems, and the many new students. After one year of teaching, some pre-service teachers abandoned their intentions to become professional teachers. Notably, PSTSS alleviated frustrations, discouragement, the effects of failures, and cultural shocks for teachers (Brady, 2016). The cooperating teachers provided all the necessary suggestions. They prepared the manual for the pre-service teachers to perform well during their practicums in schools, but each student teacher had various problems and circumstances (Hobson, 2009) that required personalized solutions. Some teachers, especially those who were distracted or reversed their intention to become teachers, reported that a one-year practicum in schools as professional development was an imposition.

\subsection{Classroom Action Research}

The second semester of the fifth year aims to promote career growth (e.g., teaching skills, classroom management techniques, and classroom action research). The teaching hours are reduced from 8 to 10 hours per week to 6 to 8 hours per week, allowing pre-service teachers to conduct classroom action research. Pre-service teachers need assistance from cooperating teachers and supervising teachers while collecting and analyzing data. However, the second semester of some schools has many school activities and holidays. Thus, they may have insufficient time to prepare and collect data for classroom action research. Their self-motivation is encouraged during the second semester, after intensively working on their classroom action research.

The question of which pre-service teachers will remain in the teaching profession is varied. Since majority of them prefer the benefits (e.g., childcare, retirement funds, lifetime health insurance and pension) but some pre-service teachers are worried of quality teaching expectations. They were educated for four years plus one year of teaching practicum and then turned away from what we expected the best out of them (Calderhead \& Sherrock, 1997). The expectations remained unclear to some of the graduates because most of them entered the profession as the first step in determining their futures. Since Thai teachers have secure futures, most of them remain in teaching professions and receive good pensions and benefits. That does not always warrant that it was the result of the succession of teacher education programs. The new models are emerging to replace the traditional five-year format, which shorten the teacher education program. Shortening the teacher education from five-year to four-year could potentially affect the effectiveness of teacher preparation program, inability to strengthen EFs among pre-service teachers, and affect the decision to sustain teaching profession (Sadler, 2006). 
The traditional five-year program has set and maintained a high standard in the teaching professions (Lombardi, 2001). Still, this program may also consume a large amount of money to invest in training a student teacher, who leaves the profession within a few years (Findlay, 2006; Hebert, 2001). Is the PSTSS worth all the effort of the professors and cooperating teachers? The answer to this question is unsettling since the PSTSS was used within a limited number of pre-service teachers, this cannot extent the result beyond the scopes of this study. Most pre-service teachers also had similar educational background, and ethonographic, therefore their responses were not different. For example, they doubted that they would pursue teaching careers if they had the insufficient intrinsic motivation and extrinsic motivation and support from their cooperating teachers and professors (Eldar, 2003). Student teachers must provide the relevant ability to present intrapersonal intelligence, vignettes of lesson planning, multiple teaching techniques, and improvements to initiatives (Meltzer, 2010) before graduating.

Encouragement and discouragement from veteran teachers benefited the pre-service teachers (Kyriacou \& O'Connor, 2003). PSTSS provided mental support, which is considered important in shaping novice teachers' identity and quality (Findlay, 2006; Flores, 2006), and when pre-service teachers experience seemingly unsolvable problems (Darling-Hammond, 1998). PSTSS helps pre-service teachers manage their mental and emotional issues. The results of this research support those of Flores (2006) and Eldar (2003): the better a pre-service teacher's support system, the more likely they are to pursuing the teaching professions. The questionnaire and in-depth interview with pre-service teachers were conducted as the key research method for this paper, which has resulted in the limiting of other empirical evidence. Further possible research could be an in-depth study of pre-service teachers in Thailand using a more holistic approach for extending data by interviewing all stakeholders such as supervisors, cooperating teachers, and teacher education program providers.

\section{Conclusion}

EFs are essential in developing student teachers that can lead to a teacher career development. PSTSS assimilates the satisfactory execution of knowledge sharing, satisfactory planning, and ongoing self-development (Findlay, 2006). Pre-service teachers who have self-control can encourage students during the teacher development process. A support system is essential in providing immediate and on-point supports, suggestions, and encouragement to pre-service teachers. The needs assessment for PSTSS demonstrates the need to develop a system that supports pre-service teachers. PSTSS is an additional part to assist pre-service teachers with teaching directions, consultations, and suggestions and to assess whether the PSTSS could affect EFs' pre-service teachers. For pre-service teachers starting a teaching career, PSTSS has improved their morals and progression.

The Thailand teacher development program has been implemented for many years but has insufficiently focused on EFs and teacher development; hence, this research assessed pre-service teachers' case studies to investigate the EFs related to teaching performance and the selection of teaching materials and activities. Further research could focus on developing EFs in students in teacher training programs, namely, before they begin teaching in schools, which could result in pre-service teachers' academic progress and development.

\section{References}

Banich, M. T. (2009). Executive Function: The Search for an Integrated Account. Current Directions in Psychological Science, 18(2), 89-94. https://doi.org/10.1111/j.1467-8721.2009.01615.x

Bellanca, J., \& Brandt, R. (2011). 21st century skills: Rethinking how students learn. Solution Tree Press.

Bowman, N. (1979). College Supervision of Student Teaching: A time to reconsider. Journal of Teacher Education, 30(3), 29-30. https://doi.org/10.1177/002248717903000310

Burstein, N. E. A., Kretschmer, D., Smith, C., \& Gudoski, P. (1999). Redesigning teacher education as a shared responsibility of schools and universities. Journal of Teacher Education, 50(2), 106-118. https://doi.org/10.1177/002248719905000204

Calderhead, J. A. S., \& Sherrock, S. B. (1997). Understanding teacher education case studies in the professional development of beginning teachers. Famler Press. Retrieved from https://library.smaratungga.web.id/repository/[Jame_Calderhead]_Understanding_Teacher_Education(Book Fi.org).pdf

Cole, A. L. (1991). Relationships in the workplace: Doing what comes naturally? Teaching and Teacher Education, 7(5-6), 415-426. https://doi.org/10.1016/0742-051X(91)90038-Q

Conley, D. T. (2005). College Knowledge: What it really takes for students to success and what we can do to get them ready. Jossey-Bass. 
Darling-Hammond, L. (1998). Teacher learning that supports student learning. Educational Leadership, 55, 6-11.

Dawson, P., \& Guare, R. (2010). Promoting executive functions in the classroom. A practical guide to assessment and intervention (2nd ed.). Guilford Press.

Eldar, E., Nabel, N., Schechter, C., Talmor, R., \& Mazin, K. (2003). Anatomy of success and failure: The story of three novice teachers. Educational Research, 45(1), 29-48. https://doi.org/10.1080/0013188032000086109

Feiman-Nemser, S. (2001). Helping novices learn to teach: Lessons from an exemplary support teacher. Journal of Teacher Education, 52(1), 17-30. https://doi.org/10.1177/0022487101052001003

Findlay, K. (2006). Context and learning factors in the development of teacher identity: A case study of newly qualified teachers during their induction year. Journal of In-Service Education, 32(4), 511-532. https://doi.org/10.1080/13674580601025165

Flores, M. A. (2004). The impact of school culture and leadership on new teachers" learning in the workplace. International Journal of Leadership in Education, 7(4), 297-318. https://doi.org/10.1080/1360312042000226918

Flores, M. A. A. D., \& Day, C. (2006). Contexts which shape and reshape new teachers' identities: A multi-perspective study. Teaching and Teacher Education, 22(2), 219-232. https://doi.org/10.1016/j.tate.2005.09.002

Gazette, T. G. (2005). Regulation of the Teachers Council of Thailand on Professional Standards and Ethics BE 2548 The Government Gazette.

Hebert, E. A. W., \& Worthy, T. (2001). Does the first year of teaching have to be a bad one? A case study of success. Teaching and Teacher Education, 17(8), 897-911. https://doi.org/10.1016/S0742-051X(01)00039-7

Hobson, A. J., Ashby, P., Malderez, A., \& Tomlinson, P. D. (2009). Mentoring beginning teachers: What we know and what we don't. Teaching and Teacher Education, 25(1), 207-216. https://doi.org/10.1016/j.tate.2008.09.001

Johnson, S. M. (1993). Pursuing a "sense of success": New teachers explain their career decisions. American Educational Research Journal, 40(3), 581-617. https://doi.org/10.3102/00028312040003581

Jones, B. K. (2016). Enduring in an "Impossible" Occupation. Journal of Teacher Education, 67(5), 437-446. https://doi.org/10.1177/0022487116668021

Jones, M. (2005). Fitting in, feeling excluded or opting out? An investigation into the socialization process of newcomers to the teaching profession in secondary schools in English. Journal of In-Service Education, 31(3), 509-526. https://doi.org/10.1080/13674580500200493

Kagan, D. M. (1992). Professional growth among preservice and beginning teachers. Review of Educational Research, 62(2), 129-169. https://doi.org/10.3102/00346543062002129

Kelley, L. M. (2004). Why induction matters. Journal of Teacher Education, 55(5), 438-448. https://doi.org/10.1177/0022487104269653

Kyriacou, C., \& O'Connor, A. (2003). Primary newly qualified teacher's experience of the induction year in its first year of implementation in England. Journal of In-Serivce Education, 29(2), 185-200. https://doi.org/10.1080/13674580300200262

Lombardi, J. (2001). Supervision of student teacher: Emerging models and innovative approaches in the USA. Teacher Development, 5(3), 309-322. https://doi.org/10.1080/13664530100200158

Loughran, J. (2014). Professionally developing a teacher educator. Journal of Teacher Education, 65(4), 271-283. https://doi.org/10.1177/0022487114533386

Meltzer, L. (2010). Executive function in education: From theory to practice. Guilford Press.

O’Brien, K., \& O'Hare, D. (2007). Situational awareness ability and cognitive skills Training in a complex real-world task. Ergonomics, 50(7), 1064-91. https://doi.org/10.1080/00140130701276640

Preston, C. (2017). University-based teacher preparation and middle grades teacher effectiveness. Journal of Teacher Education, 68(1), 102-116. https://doi.org/10.1177/0022487116660151

Sadler, T. D. (2006). "I won't last three weeks": Preservice science teachers reflect on their student-teaching experiences. Journal of Science Teacher Education 17, 217-241.

https://doi.org/10.1007/s10972-005-9004-1 
Smagorinsky, P., \& Jordahl, A. (1991). The student teacher/cooperating teacher collaborative study: A new source of knowledge. English Education, 23(1), 54-59. Retrieved from http://www.jstor.org/stable/40172750

Sulpeter, J. (2003, October 15). 21 st century skills: Will our students be prepared? Retrieved from http://www.techlearning.com/news/0002/21st-century-skills-will-our-students-be-prepared/64781

\section{Copyrights}

Copyright for this article is retained by the author(s), with first publication rights granted to the journal.

This is an open-access article distributed under the terms and conditions of the Creative Commons Attribution license (http://creativecommons.org/licenses/by/4.0/). 